\title{
Minimally invasive surgery for benign intradural extramedullary spinal meningiomas: experience of a single institution in a cohort of elderly patients and review of the literature
}

\author{
This article was published in the following Dove Press journal: \\ Clinical Interventions in Aging \\ 5 December 2012 \\ Number of times this article has been viewed
}

\section{Maurizio lacoangeli \\ Maurizio Gladi \\ Alessandro Di Rienzo \\ Mauro Dobran \\ Lorenzo Alvaro \\ Niccolò Nocchi \\ Lucia Giovanna Maria \\ Di Somma \\ Roberto Colasanti \\ Massimo Scerrati}

Department of Neurosurgery, Università Politecnica delle Marche, Umberto I General Hospital, Ancona, Italy
Correspondence: Maurizio lacoangeli

Clinica di Neurochirurgia, Università

Politecnica delle Marche, Ospedali

Riuniti di Ancona, Via Conca 7I,

Ancona, Italy 60020

Tel +39 07। 5964567

Fax +39 07I 5964575

Email mauriziogladi@gmail.com

\begin{abstract}
Meningiomas of the spine are the most common benign intradural extramedullary lesions and account for $25 \%-46 \%$ of all spinal cord tumors in adults. The goal of treatment is complete surgical resection while preserving spinal stability. Usually, these lesions occur in the thoracic region and in middle-aged women. Clinical presentation is usually nonspecific and the symptoms could precede the diagnosis by several months to years, especially in older people, in whom associated age-related diseases can mask the tumor for a long time. We report a series of 30 patients, aged 70 years or more, harboring intradural extramedullary spinal meningiomas. No subjects had major contraindications to surgery. A minimally invasive approach (hemilaminectomy and preservation of the outer dural layer) was used to remove the tumor, while preserving spinal stability and improving the watertight dural closure. We retrospectively compared the outcomes in these patients with those in a control group subjected to laminectomy or laminotomy with different dural management. In our experience, the minimally invasive approach allows the same chances of complete tumor removal, while providing a better postoperative course than in a control group.
\end{abstract}

Keywords: spinal meningioma, elderly, hemilaminectomy, outer dural layer, inner dural layer, minimally invasive surgery

\section{Introduction}

Spinal meningiomas constitute approximately $25 \%$ of all spinal neoplasms. ${ }^{1}$ There is a female predominance and nearly $80 \%$ of these tumors occur in the thoracic spine, followed in frequency by the cervical and lumbar regions. ${ }^{2-6}$ The majority are benign lesions, classically localized lateral to the spinal cord in an intradural extramedullary position. ${ }^{1,7}$ These tumors primarily affect middle-aged subjects but, with increasing life expectancy, symptomatic spinal meningiomas are being observed more frequently in elderly patients. ${ }^{8,9}$ The primary goal of spinal tumor surgery is to decompress the spinal cord and/or the roots involved by radical resection of the lesion, without creating spinal instability or worsening the preoperative neurological status. Choice of optimal surgical route mostly depends on the location and size of the tumor, but also on patient status and surgeon preference. ${ }^{10}$ Posterior and lateral spinal meningiomas are generally approached via the posterior route, although some reports have demonstrated the feasibility of this route for ventral lesions as well. ${ }^{11-20}$ Conventional laminectomy provides a good working area, but several drawbacks still exist, including less protection in the event of a hematoma, possible constriction of the dura by epidural 
scarring, difficulty if a second surgery is required, and a high risk of postoperative spinal deformity. ${ }^{21-27}$ All these complications could result in a poor outcome, especially in frail elderly patients. This has led some surgeons to perform less invasive approaches, such as laminotomy, laminoplasty, and hemilaminectomy. ${ }^{28}$

Currently, when applicable, we prefer to perform a hemilaminectomy or partial hemilaminectomy with an interlaminar approach because it offers some advantages, including a shorter operative time, decreased intraoperative blood loss, and particularly a reduced risk of postoperative spinal instability. ${ }^{29-42} \mathrm{~A}$ controversial point in the literature concerns the best management of the dural attachment that is commonly resected or coagulated. ${ }^{43} \mathrm{We}$ have used another technique in our patients, first described by Saito et al in 2001, involving separation of the dura into an outer and inner layer, with the inner layer removed together with the tumor and the outer layer used for primary dural closure. ${ }^{44}$ Here we review our 5 years of experience with intradural extramedullary spinal meningiomas in older subjects ( $>70$ years) treated by techniques that are less invasive for both bony and dural structures, evaluating the impact of minimally invasive versus conventional approaches for tumor removal and spinal stability.

\section{Materials and methods}

From January 2005 to December 2010, 30 elderly patients harboring spinal intradural extramedullary meningiomas were treated using a minimally invasive approach of hemilaminectomy and dural splitting. Mean age at presentation was 74.6 years. Ten patients were men and 20 were women. The diagnosis was made by contrast-enhanced magnetic resonance imaging (MRI) in 27 subjects and by computed tomography scan due to the presence of a cardiac pacemaker in three patients. No patient had major contraindications to surgery. Laminotomy or laminectomy with a traditional posterior midline approach and dural coagulation/resection was used in another 35 elderly subjects operated for spinal meningioma between January 1998 and December 2004. This latter group of patients was selected because they had characteristics similar to the first ones (Table 1). Because of the wide range in follow-up duration, the patients were compared 2 years after surgery. When possible, MRI was the diagnostic test of choice for assessing the extent of resection. If the postoperative course was uneventful and the immediate computed tomography scan was satisfactory, clinical and radiological (MRI) follow-up was performed at 3 and 6 months, and every year thereafter. On the other hand,

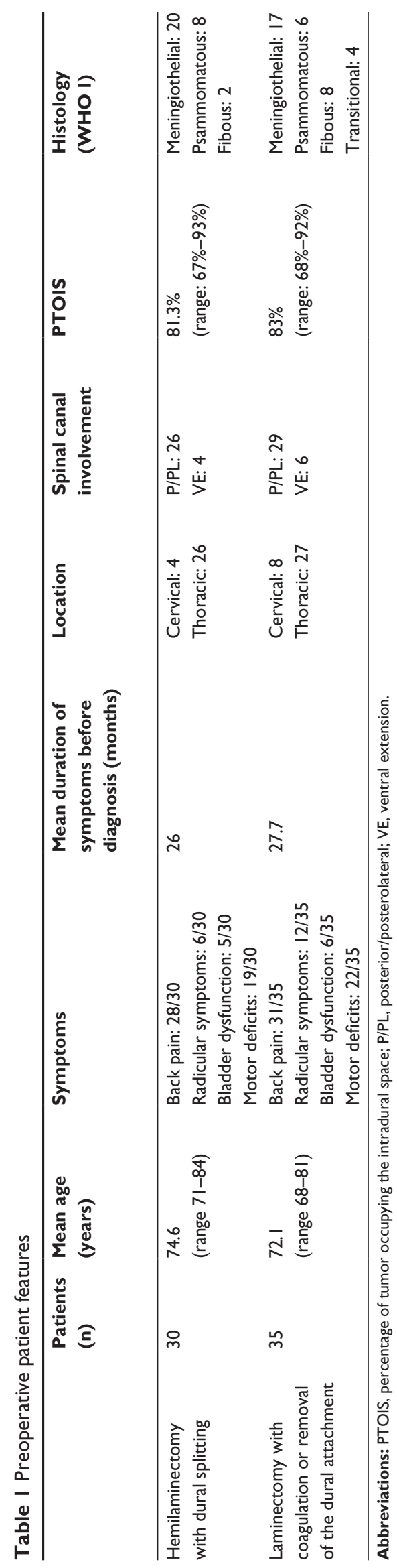




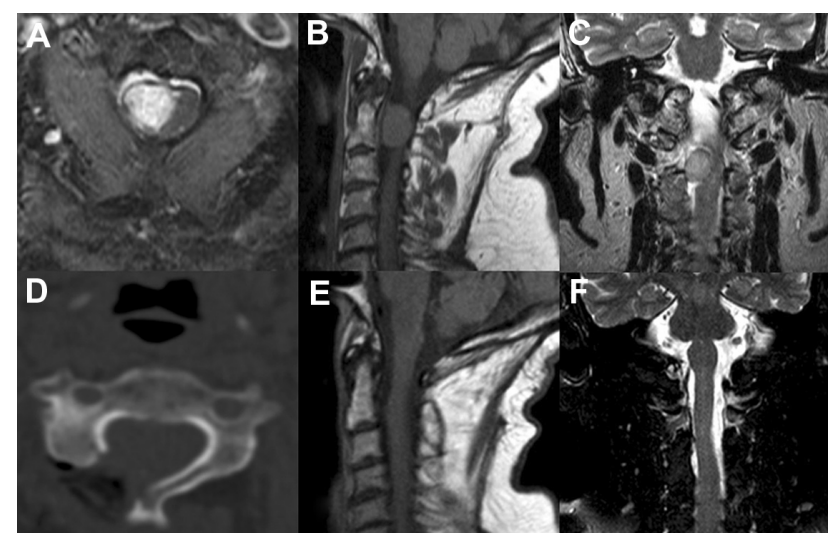

Figure I Illustrative case I. (A-C) Preoperative axial, sagittal, and coronal magnetic resonance images showing a right upper cervical spine meningioma. (D) Postoperative computed tomography scan showing the unilateral approach. (E and F) Postoperative MRI demonstrating complete removal of the lesion.

in the event of suspected postoperative spinal instability, a dynamic x-ray was performed. Figures 1 and 2 show two illustrative cases.

After careful preoperative planning, the patient was placed in the prone position under general anesthesia and a midline skin incision centered on the lesion was made. Somatosensory and transcranial motor evoked potentials along with free running electromyographies were monitored. Unilateral subperiosteal muscle dissection was carried out and the lamina or laminae were exposed. Depending on tumor size, we performed a monosegmental or multisegmental hemilaminectomy above and below the tumor. In the event of smaller lesions, a partial hemilaminectomy of the two

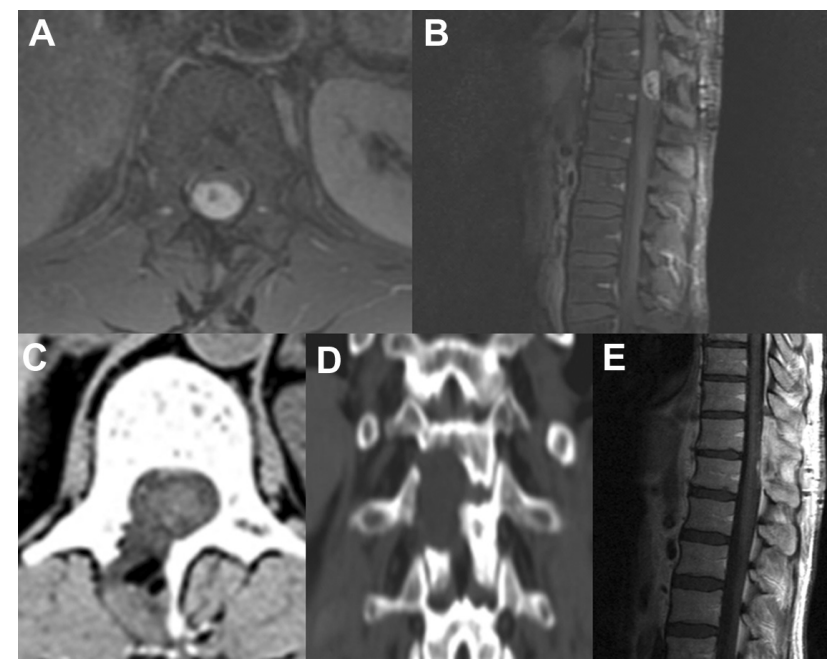

Figure 2 Illustrative case 2. (A and B) Preoperative axial and sagittal magnetic resonance images showing a meningioma of the thoracolumbar junction (C and D) Postoperative axial and coronal computed tomographic scan demonstrating the minimally invasive unilateral approach. (E) Postoperative magnetic resonance image showing complete tumor resection. contiguous laminae was preferred, using an interlaminar approach. The flavum ligamentum was removed until the contralateral root or dural curve was seen. Partial facetectomy $(<50 \%)$, undercutting of the base of the spinous processes and contralateral lamina, oblique tilting of the operating table, or an endoscopy-assisted microsurgical technique were sometimes employed to visualize the contralateral side of the spinal canal better. Tumor resection was carried out using the technique described by Saito et al. ${ }^{44}$ Under microscope vision, a small incision within the outer layer of the dura was made, which was stripped away from the inner layer using microforceps and microdissectors (Figure 3A). The tumor base could then be seen through

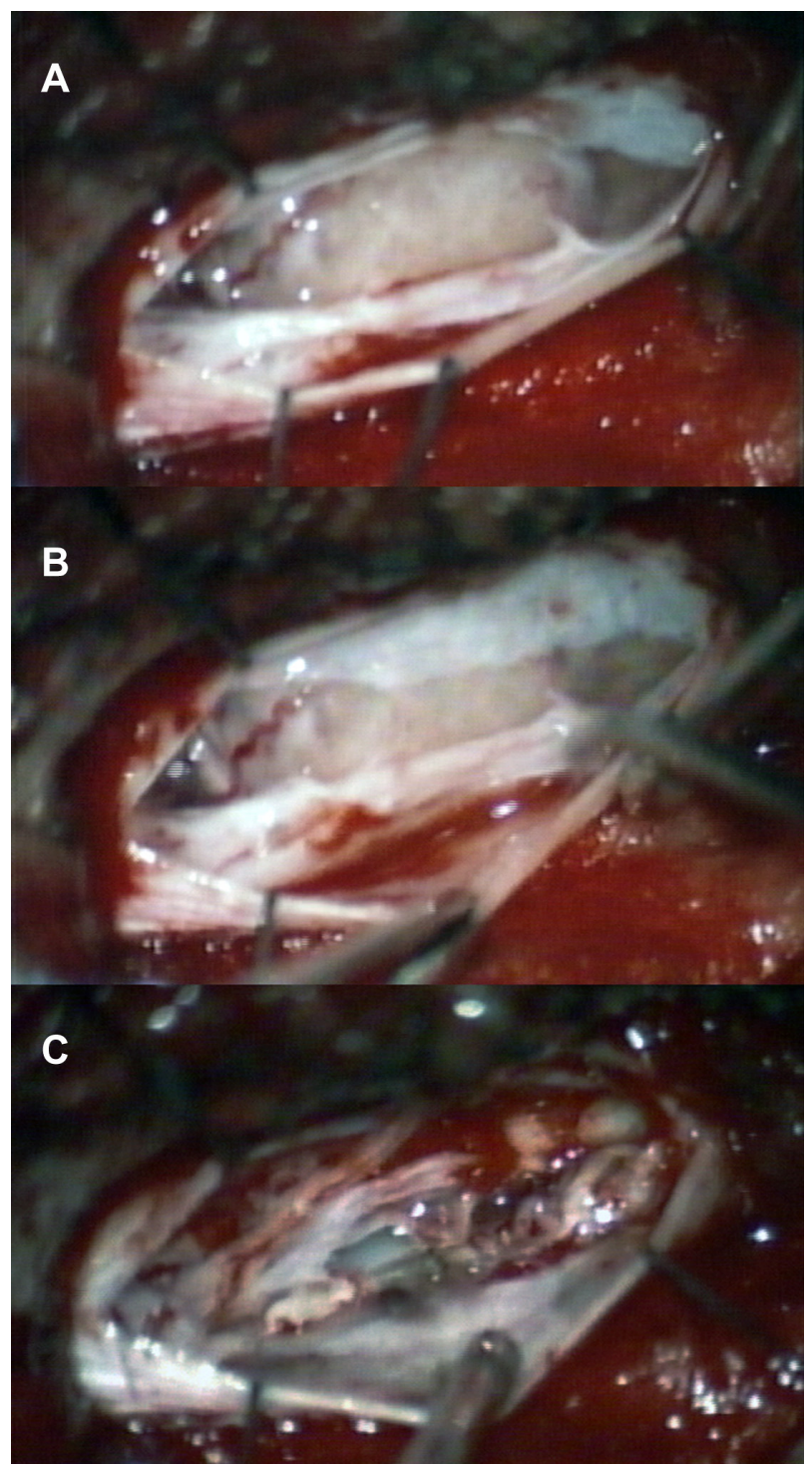

Figure 3 Intraoperative images. (A and B) Intraoperative evidence of two dural layers with the spinal meningioma attachment to the inner layer. (C) Final view demonstrating the preserved outer dural layer as well as complete removal of the lesion together with the inner dural layer. 
the inner layer of the dura. After retracting the outer dural layer with stay sutures, a small incision was made with a microscalpel in the inner layer and continued around the tumor base. The lesion was freed from the surrounding dura and then carefully lifted up, using the arachnoid or pia membrane between the meningioma and spinal cord as a dissection plane (Figure 3B). Internal tumor debulking or its piecemeal resection helps the dissection and increase the working space. In the event of a lesion with ventral spreading, the dentate ligament was cut before internal decompression in order to facilitate handling of the spinal cord and avoid excessive mechanical retraction. After removal of the meningioma, the preserved outer dural layer was used to close the dura in a watertight fashion (Figure 3C). Fibrin glue and fat were applied epidurally to reinforce the closure.

\section{Results}

Gross total tumor removal was obtained in 28 patients and was subtotal in two cases in the group treated with hemilaminectomy and dural splitting. Mean operative time was 145 minutes. There was no major postoperative morbidity or mortality. No patient required additional surgery because of progressive spinal instability. Cerebrospinal fluid leak was observed in one patient with spontaneous resolution. The mean duration of hospital stay was 5.83 days. In elderly patients treated with a conventional technique and different dural management, the degree of tumor removal and recovery from neurological deficits was similar to that in the first group of subjects. The main postoperative differences concerned long-term posterior cervical and dorsal pain, radiological instability needing fixation, mean duration of the surgical procedure, length of hospital stay, number of cerebrospinal fluid leaks, and return to normal daily activities (Table 2). These results were not statistically significant.

\section{Discussion}

Treatment of subjects with intradural extramedullary spinal meningioma has changed over the past 20 years. Advances in many disciplines, including neuroradiology, neurosurgery, neuro-oncology, and neuropathology, have contributed substantially to improving outcomes for patients. Despite this, delayed diagnosis still occurs, particularly in elderly patients, because symptoms can be misinterpreted and attributed to pre-existing or age-related diseases, such as degenerative spinal pathology, parkinsonism, and diabetic neuropathy. ${ }^{4,5,15,45,46}$ The hesitation in performing spinal surgery in aged people may be related to the expectation of higher intraperioperative risk. ${ }^{47}$ However, various operations,

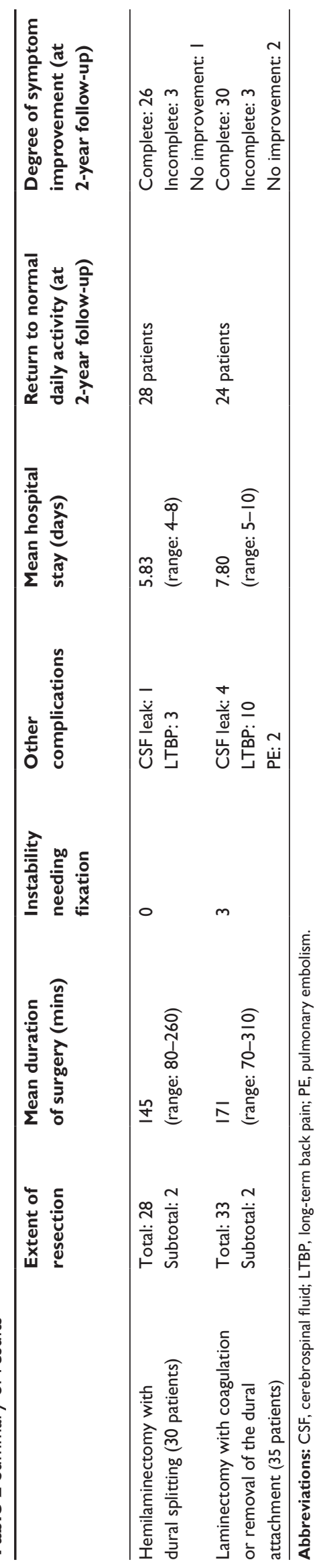


such as hip surgery, transurethral prostate resection, heart valve replacement, and coronary artery bypass surgery, are procedures performed routinely in large numbers of elderly patients. ${ }^{48}$ Moreover, several clinical studies have demonstrated that spinal meningiomas have a good prognosis regardless of preoperative clinical findings, and even patients with a poor preoperative neurological status can respond favorably to surgery. ${ }^{6,49,50} \mathrm{We}$ are aware of the radiotherapy option, but think that when possible, microsurgical tumor removal still represents the best therapeutic option in older people as well. ${ }^{51,52}$ Radical removal of the lesion and preservation of spinal stability are the goals of surgery for these benign tumors, but some concerns arise as to what is the best way to do it.

\section{Posterior approach}

Tumor location is one of the most important factors affecting the clinical outcome. ${ }^{29}$ Spinal meningiomas are usually localized lateral to the spinal cord, but $15 \%-27 \%$ of cases are located anteriorly and constitute a surgical challenge.? Although none of our patients had a purely ventral (anterior to the dentate ligament) meningioma, we believe that in aged subjects, if possible, a posterior approach needs to be used, regardless of tumor location. This route, in association with modern microsurgical and endoscopic techniques, provides adequate exposure to remove the vast majority of lesions safely. The risks related to the anterior approaches, in some patients, are not conterbalanced by benign nature of the tumor and long survival. ${ }^{11,15,17,19,53}$ Furthermore, as in some of our patients, dentate ligament division, gentle cord rotation, and internal tumor decompression can provide additional space to deal with more anterior tumors. ${ }^{1,11,53}$ However, in cases of ventral intradural lesions, anterior approaches are necessary, ie, for heavily calcified, densely fibrotic, highly vascular, or en plaque meningiomas with ventral attachment, and should be considered under appropriate circumstances. ${ }^{53}$

Fortunately, we had only two cases with very dense adhesions (one meningioma was lateral in position and the other one was ventrolateral) and both these patients underwent a posterior unilateral approach with subtotal lesion removal. In fact, the tendency of some psammomatous meningiomas toward pial invasion is well known in the literature. ${ }^{9}$ Posterior spinal approaches include laminectomy (removal of the spinous process and lamina), laminotomy (removal and subsequent reinsertion of the spinous process and lamina), laminoplasty (hinging of the lamina to allow access or reconstruction of the spinal canal), hemilaminectomy (unilateral removal of the lamina), and percutaneous techniques. ${ }^{28,39,54}$

\section{Hemilaminectomy}

Total laminectomy is the conventional approach and has been used for surgical removal of spinal cord tumors. It offers some advantages to surgeons, such as familiar exposure and a wide view of the surgical field. However, this technique has some drawbacks that can complicate the postoperative outcome. It can produce spinal instability, epidural fibrosis, and postoperative axial pain. ${ }^{21-27,38}$ Postlaminectomy kyphosis is well recognized and commonly associated with instability, resulting in anterior compression of the spinal cord that can cause progressive myelopathy. ${ }^{30,41,55}$ Various alternative procedures were developed to reduce the risk of complications following laminectomy. Some authors have described the advantages of laminoplasty or laminotomy in maintaining postoperative stability and preventing epidural scarring. ${ }^{35,42,56}$ On the other hand, Asazuma et al reported that extensive laminoplasty, although able to decrease spinal instability and the deformity rate, cannot completely prevent the progressive postoperative deformation of the normal spinal curvature. ${ }^{41}$ However, these techniques are somewhat difficult, time-consuming, and have a high risk of dural laceration, especially in the elderly where the dura is thinner. ${ }^{57}$ Although laminectomy, laminoplasty, and laminotomy require different degrees of bone removal, they all involve bilateral surgical stripping and denervation of posterior muscular and ligamentous structures that are essential for maintaining spinal stability. ${ }^{27}$

Considering these issues, some authors have tried to reduce the surgical trauma by performing hemilaminectomy, which has a lower impact on spinal biomechanics. ${ }^{33-37,58,59}$ The rationale for hemilaminectomy involves preservation of the contralateral lamina, maintenance of the so-called "tension band", and maintenance of the integrity of the supraspinous/interspinous ligaments and the contralateral paravertebral musculature..$^{32,60}$ One possible disadvantage of unilateral hemilaminectomy is the narrow surgical corridor formed by the spinous process and ipsilateral facet joint that could increase the risk of dural tearing, nerve root damage, or incomplete tumor removal. However, undercutting of the base of the spinous process and contralateral lamina, facetectomy limited to $<50 \%$ (Figures $1 \mathrm{D}$ and $2 \mathrm{C}$ ), oblique tilting of the operating table, and an endoscopy-assisted microsurgical technique help the surgeon to control the contralateral side of the spinal cord, thus allowing safer dissection of the tumor. ${ }^{27,61,62}$ Yeo et al described another way to obtain more surgical space which involves ipsilateral dural tacking and suture with the base of the muscle or fascia near the facet joint, instead of lifting it up or suspending it. ${ }^{38}$ 
Although hemilaminectomy proved to be a very promising and versatile procedure in several previous reports and in our patients, we are aware that there may be situations which are not fully manageable using this minimally invasive technique. ${ }^{37}$ Tumors that involve the contralateral recess, bilateral extradural lesions, huge neoplasms with scalloping of vertebrae, easily bleeding tumors spreading to both sides, lesions with unclear borders, and intramedullary neoplasms may be difficult to manage using this approach. ${ }^{30,31,55}$

\section{Dural management}

Treatment of tumor dural attachment is still a matter of debate. Resection of the dura mater involved (Simpson grade I), coagulation of the dural attachment (Simpson grade II), and peeling off of the inner dural layer from the outer one are three common procedures described in the literature. ${ }^{43,44,63}$ Grade I Simpson resection is the most radical treatment option for spinal meningioma, although some reports have not confirmed the need for complete resection of the dura involved, and the long-term results of this technique have yet to be validated. ${ }^{1,4,6,15,18,50}$ Moreover, such aggressive treatment of the dura may increase the risk of cerebrospinal fluid leak. ${ }^{18}$ Our policy, consistent with the literature, is to perform a grade I Simpson resection in young subjects ( $<50$ years) harboring meningioma with interdural/ extradural extension, heavy calcification, and aggressive behavior (grade II-IV tumors). ${ }^{7,64}$ Cauterization of the dura mater attachment offers acceptable long-term results in terms of tumor recurrence rates, while the risk of postsurgical cerebrospinal fluid leak is markedly reduced in the event of pure intradural meningioma. ${ }^{11,15,17-19,65}$ However, we think that excessive coagulation in a very thin and adherent dura, as often found in elderly patients, may cause its perforation or shrinkage and thus jeopardize primary dural closure. In the present series, we used the technique described by Saito et al, consisting of dural splitting into an outer and inner layer with removal of the meningioma en bloc along with the inner dural stratum (Figure 3). ${ }^{44}$ We have chosen this method to deal with the dural implant because of the advanced age of our patients, tumor features, and the possibility of obtaining a primary watertight dural closure using the preserved outer dural layer.

\section{Our experience}

The present study has some limitations due to the small number of patients, the short follow-up duration in some subjects, and the retrospective nature of our observations. However, our minimally invasive approach (hemilaminectomy and dural splitting) is relatively simple and straightforward, allowing good results in terms of total resection and postoperative quality of life. Compared with the group treated conventionally, our elderly subjects, who underwent a minimally invasive technique, experienced reduced intraoperative blood loss, a briefer surgical procedure, a shortened hospital stay, less cerebrospinal fluid leak, improved wound healing, faster recovery, and less disabling cervical and/or dorsal pain. All these benefits allow for earlier ambulation and rehabilitation, which are the major targets for good postoperative quality of life in patients, particularly elderly ones. We did not identify any disadvantages of hemilaminectomy in our patients, but if the surgeon feels unable to remove the tumor by this technique, the unilateral approach can be easily and quickly converted to a conventional laminectomy.

\section{Conclusion}

A minimally invasive approach and primary dural closure associated with good neuroanesthesia along with excellent preoperative postoperative care should be, in our opinion, the preferred way to manage elderly patients with spinal meningioma. The message of this paper is three-fold. The first relates to the preservation of spinal stability as a result of hemilaminectomy. The second emphasizes the importance of primary dural closure. The third concerns the posterior approach as the route of choice, whenever possible. All these issues have led us to tailor our surgical treatment to the individual patient, aiming to achieve the best possible result both in terms of tumor removal and functional outcome.

\section{Disclosure}

The authors report no conflicts of interest in this work.

\section{References}

1. Voulgaris S, Alexiou GA, Mihos E, et al. Posterior approach to ventrally located spinal meningiomas. Eur Spine J. 2010;19(7):1195-1199.

2. Hirabayashi H, Takahashi J, Kato H, Ebara S, Takahashi H. Surgical resection without dural reconstruction of a lumbar meningioma in an elderly woman. Eur Spine J. 2009;18 Suppl 2:232-235.

3. Helseth A, Mørk SJ. Primary intraspinal neoplasms in Norway, 1955 to 1986. A population-based survey of 467 patients. J Neurosurg. 1989;71(6):842-845.

4. Levy WJ Jr, Bay J, Dohn D. Spinal cord meningioma. J Neurosurg. 1982;57(6):804-812.

5. Roux FX, Nataf F, Pinaudeau M, Borne G, Devaux B, Meder JF. Intraspinal meningiomas: review of 54 cases with discussion of poor prognosis factors and modern therapeutic management. Surg Neurol. 1996;46(5):458-464.

6. Solero CL, Fornari M, Giombini S, et al. Spinal meningiomas: review of 174 operated cases. Neurosurgery. 1989;25(2):153-160.

7. Cohen-Gadol AA, Zikel OM, Koch CA, Scheithauer BW, Krauss WE. Spinal meningiomas in patients younger than 50 years of age: a 21-year experience. J Neurosurg. 2003;98 Suppl 3:258-263. 
8. Morandi X, Haegelen C, Riffaud L, Amlashi S, Adn M, Brassier G. Results in the operative treatment of elderly patients with spinal meningiomas. Spine (Phila Pa 1976). 2004;29(19):2191-2194.

9. Schaller B. Spinal meningioma: relationship between histological subtypes and surgical outcome? J Neurooncol. 2005;75(2):157-161.

10. Payer M, Radovanovic I, Jost G. Resection of thoracic dumbbell neurinomas: single postero-lateral approach or combined posterior and transthoracic approach? J Clin Neurosci. 2006;13(6):690-693.

11. Kim CH, Chung CK. Surgical outcome of a posterior approach for large ventral intradural extramedullary spinal cord tumors. Spine (Phila Pa 1976). 2011;36(8):E531-E537.

12. Beall DP, Googe DJ, Emery RL, et al. Extramedullary intradural spinal tumors: a pictorial review. Curr Probl Diagn Radiol. 2007;36(5): 185-198.

13. Slin'ko EI, Al-Qashqish II. Intradural ventral and ventrolateral tumors of the spinal cord: surgical treatment and results. Neurosurg Focus. 2004;17(1):ECP2.

14. Conti P, Pansini G, Mouchaty H, Capuano C, Conti R. Spinal neurinomas: retrospective analysis and long-term outcome of 179 consecutively operated cases and review of the literature. Surg Neurol. 2004;61(1):34-44.

15. Klekamp J, Samii M. Surgical results for spinal meningiomas. Surg Neurol. 1999;52(6):552-562.

16. Arnautović KI, Al-Mefty O, Husain M. Ventral foramen magnum meningiomas. J Neurosurg. 2000;92 Suppl 1:71-80.

17. Bassiouni H, Ntoukas V, Asgari S, Sandalcioglu EI, Stolke D, Seifert V. Foramen magnum meningiomas: clinical outcome after microsurgical resection via a posterolateral suboccipital retrocondylar approach. Neurosurgery. 2006;59(6):1177-1187.

18. Boström A, Bürgel U, Reinacher P, et al. A less invasive surgical concept for the resection of spinal meningiomas. Acta Neurochir (Wien). 2008;150(6):551-556.

19. Setzer M, Vatter H, Marquardt G, Seifert V, Vrionis FD. Management of spinal meningiomas: surgical results and a review of the literature. Neurosurg Focus. 2007;23(4):E14.

20. Steck JC, Dietze DD, Fessler RG. Posterolateral approach to intradural extramedullary thoracic tumors. J Neurosurg. 1994;81(2):202-205.

21. Jönsson B, Annertz M, Sjöberg C, Strömqvist B. A prospective and consecutive study of surgically treated lumbar spinal stenosis. Part II: five years follow-up by an independent observer. Spine (Phila Pa 1976). 1997;22(24):2938-2944.

22. Iida Y, Kataoka O, Sho T, et al. Postoperative lumbar spinal instability occurring or progressing secondary to laminectomy. Spine (Phila Pa 1976). 1990;15(11):1186-1189.

23. Lonstein JE. Postlaminectomy spinal deformity. In: Lonstein JE, Bradford DS, Winter RB, Ogilvie JW, editors. Moe's Textbook of Scoliosis and Other Spinal Deformities, 3rd ed. Philadelphia, PA: WB Saunders; 1995.

24. Mayfield FH. Complications of laminectomy. Clin Neurosurg. 1976;23: 435-439.

25. Winter RB, Hall JE. Kyphosis in childhood and adolescence. Spine (Phila Pa 1976). 1978;3(4):285-308.

26. Yasuoka S, Peterson HA, MacCarty CS. Incidence of spinal column deformity after multilevel laminectomy in children and adults. J Neurosurg. 1982;57(4):441-445.

27. Yaşargil MG, Tranmer BI, Adamson TE, Roth P. Unilateral partial hemi-laminectomy for the removal of extra- and intramedullary tumours and AVMs. Adv Tech Stand Neurosurg. 1991;18:113-132.

28. Yucesoy K, Sonntag VK. Terminology confusion in spinal surgery: laminotomy, laminoplasty, laminectomy. J Neurosurg. 2000;92(2): 371.

29. Canbay S, Hasturk AE, Basmaci M, Erten F, Harman F. Management of thoracal and lumbar schwannomas using a unilateral approach without instability: an analysis of 15 cases. Asian Spine J. 201;6(1):43-49.

30. Bertalanffy H, Mitani S, Otani M, Ichikizaki K, Toya S. Usefulness of hemilaminectomy for microsurgical management of intraspinal lesions. Keio J Med. 1992;41(2):76-79.
31. Naganawa T, Miyamoto K, Hosoe H, Suzuki N, Shimizu K Hemilaminectomy for removal of extramedullary or extradural spinal cord tumors: medium to long-term clinical outcomes. Yonsei Med J. 2011;52(1):121-129.

32. Sun CX, Meng XL, Xie SN, Yu Y, Yang HJ, Wu B. Unilateral hemilaminectomy for patients with intradural extramedullary tumors. J Zhejiang Univ Sci B. 2011;12(7):575-581.

33. Taylor AS. Unilateral laminectomy. Ann Surg. 1910;51(4):529-533.

34. Panjabi MM, White AA 3rd. Basic biomechanics of the spine. Neurosurgery. 1980;7(1):76-93.

35. Oktem IS, Akdemir H, Kurtsoy A, Koç RK, Menkü A, Tucer B. Hemilaminectomy for the removal of the spinal lesions. Spinal Cord. 2000;38(2):92-96.

36. Ogden AT, Bresnahan L, Smith JS, Natarajan R, Fessler RG. Biomechanical comparison of traditional and minimally invasive intradural tumor exposures using finite element analysis. Clin Biomech (Bristol, Avon). 2009;24(2):143-147.

37. Chiou SM, Eggert HR, Laborde G, Seeger W. Microsurgical unilateral approaches for spinal tumor surgery: eight years' experience in 256 primary operated patients. Acta Neurochir (Wien). 1989;100(3-4): $127-133$.

38. Yeo DK, Im SB, Park KW, Shin DS, Kim BT, Shin WH. Profiles of spinal cord tumors removed through a unilateral hemilaminectomy. J Korean Neurosurg Soc. 2011;50(3):195-200.

39. Mannion RJ, Nowitzke AM, Efendy J, Wood MJ. Safety and efficacy of intradural extramedullary spinal tumor removal using a minimally invasive approach. Neurosurgery. 2011;68 Suppl Operative 1:208-216.

40. Yu Y, Zhang X, Hu F, Xie T, Gu Y. Minimally invasive microsurgical treatment of cervical intraspinal extramedullary tumors. J Clin Neurosci. 2011;18(9):1168-1173.

41. Asazuma T, Nakamura M, Matsumoto M, Chibo K, Toyama Y. Postoperative changes of spinal curvature and range of motion in adult patients with cervical spinal cord tumors: analysis of 51 cases and review of the literature. J Spinal Disord Tech. 2004;17(3):178-182.

42. Balak N. Unilateral partial hemilaminectomy in the removal of a large spinal ependymoma. Spine J. 2008;8(6):1030-1036.

43. Yamamuro K, Seichi A, Kimura A, et al. Histological investigation of resected dura mater attached to spinal meningioma. Spine (Phila Pa 1976). 2012;37(22):E1398-E1401.

44. Saito T, Arizono T, Maeda T, Terada K, Iwamoto Y. A novel technique for surgical resection of spinal meningioma. Spine (Phila Pa 1976). 2001;26(16):1805-1808.

45. Huang CY, Matheson J. Spinal cord tumors in the elderly. Aust N Z J Med. 1979;9(5):538-541.

46. Khodadad G. Common errors in the diagnosis of spinal meningiomas. Geriatrics. 1973;28(1):143-145.

47. Dripps RD, Lamont A, Eckenhoff JE. The role of anesthesia in surgical mortality. JAMA. 1961;178:261-266.

48. McIntyre AB, Ballenger JF, King AT. Coronary artery bypass surgery in the elderly. J S C Med Assoc. 1990;86(8):435-439.

49. Gezen F, Kakraham S, Canakci Z, Bedük A. Review of 36 cases of spinal cord meningiomas. Spine (Phila Pa 1976). 2000;25(6):727-731.

50. Gottfried ON, Gluf W, Quinones-Hinojosa A, Kan P, Schmidt MH. Spinal meningiomas: surgical management and outcome. Neurosurg Focus. 2003;14(6):e2.

51. Sachdey S, Dodd RL, Chang SD, et al. Stereotactic radiosurgery yields long-term control for benign intradural, extramedullary spinal tumors. Neurosurgery. 2011;69(3):533-539.

52. Postalci L, Tugcu B, Gungor A, Guclu G. Spinal meningiomas: recurrence in ventrally located individuals on long-term follow-up; a review of 46 operated cases. Turk Neurosurg. 2011;21(4):449-453.

53. Angevine PD, Kellner C, Haque RM, McCormick PC. Surgical management of ventral intradural spinal lesions. J Neurosurg Spine. 2011;15(1):28-37.

54. Lu DC, Dhall SS, Mummaneni PV. The transspinous mini-open approach for resection of intradural spinal neoplasms: cadaveric feasibility study and report of 3 clinical cases. World Neurosurg. 2010;74(1):195-199. 
55. Ozawa H, Kokubun S, Aizawa T, Hoshikawa T, Kawahara C. Spinal dumbbell tumors: an analysis of a series of 118 cases. J Neurosurg Spine. 2007;7(6):587-593.

56. Song YK, Jahng TA. The usefulness of laminoplasty in cervical spinal cord tumor surgery. J Korean Neurosurg Soc. 2004;35(3):261-266.

57. Parkinson D. Replacement laminotomy. Surg Neurol. 1977;8(4): 277-279.

58. Abbott R, Feldstein N, Wisoff N, Epstein FJ. Osteoplastic laminotomy in children. Pediatr Neurosurg. 1992;18(3):153-156.

59. Eggert HR, Scheremet R, Seeger W, Gaitzsch J. Unilateral microsurgical approaches to extramedullary spinal tumors. Operative technique and results. Acta Neurochir. 1983;67(3-4):245-253.

60. Hotta H. An experimental study on stability of human spine, especially the role of the lumbar ligaments. J Jpn Orthop Assoc. 1976;50:1-14.
61. Tredway TL, Santiago P, Hrubes MR, Song JK, Christie SD, Fessler RG. Minimally invasive resection of intradural-extramedullary spinal neoplasms. Neurosurgery. 2006;58(Suppl 1):ONS52-ONS58.

62. Zdeblick TA, Zou D, Warden KE, McCabe R, Kunz D, Vanderby R. Cervical stability after foraminotomy. J Bone Joint Surg Am. 1992; 74(1):22-27.

63. Ahn DK, Park HS, Choi DJ, Kim KS, Kim TW, Park SY. The surgical treatment for spinal intradural extramedullary tumors. Clin Orthop Surg. 2009;1(3):165-172.

64. Nakamura M, Tsuji O, Fujiyoshi K, et al. Long-term surgical outcomes of spinal meningiomas. Spine (Phila Pa 1976). 2012;37(10): E617-E623.

65. Schick U, Marquardt G, Lorenz R. Recurrence of benign spinal neoplasms. Neurosurg Rev. 2001;24(1):20-25.
Clinical Interventions in Aging

\section{Publish your work in this journal}

Clinical Interventions in Aging is an international, peer-reviewed journal focusing on evidence-based reports on the value or lack thereof of treatments intended to prevent or delay the onset of maladaptive correlates of aging in human beings. This journal is indexed on PubMed Central, MedLine, the American Chemical Society's 'Chemical Abstracts

\section{Dovepress}

Service' (CAS), Scopus and the Elsevier Bibliographic databases. The manuscript management system is completely online and includes a very quick and fair peer-review system, which is all easy to use. Visit http://www.dovepress.com/testimonials.php to read real quotes from published authors. 